\title{
The influence of 2-aminoethoxydiphenyl borate on the electrical activity of the rat heart under hypoxia/reoxygenation conditions
}

\author{
Elena Kharkovskaya ${ }^{a}$, Grigory V. Osipov ${ }^{\mathrm{a}}$, Irina V. Mukhina ${ }^{\mathrm{a}, \mathrm{b}}$ \\ 603950, unn.ru \\ Nizhny Novgorod, Russia, 603950, pimunn.ru \\ Corresponding author: Elena Kharkovskaya \\ e-mail: elharkov@gmail.com \\ postal address: 33 Krasnozvezdnaya street 64, Nizhny Novgorod, Russia, 603104 \\ Co-author's e-mails: Dr. G.V. Osipov, grosipov@gmail.com \\ Dr. I.V. Mukhina, mukhinaiv@mail.ru
}

${ }^{a}$ Lobachevsky State University of Nizhny Novgorod, 23 Gagarin Avenue, Nizhny Novgorod, Russia,

${ }^{\mathrm{b}}$ Federal State Budgetary Educational Institution of Higher Education «Privolzhsky Research Medical University» of the Ministry of Health of the Russian Federation, 10/1, Minin and Pozharsky Sq.,

Keywords: Multi-electrode mapping, isolated heart, 2-aminoethoxydiphenyl borate, fibrillation, hypoxia/reoxygenation injury

\begin{abstract}
The aim of the study was to apply the multi-electrode mapping method to investigate the effect of 2-aminoethoxydiphenyl borate (2-apb) on the electrical activity and vessels of the isolated rat heart under hypoxia/reoxygenation injury (H/R). To date, the ability to influence on the calcium currents and condition of gap junctions has been shown for 2-apb. Changes in the intracellular calcium concentration in the heart play the pivotal role in the development of H/R.

As a result, it was shown that 2-apb influences on the myocardial conduction velocity, sinus rhythm and coronary blood flow in the isolated rat heart. 2-apb caused heart fibrillation during normoxia but not under hypoxia, and attenuated the effect of the H/R on heart rate and vascular function.

\section{Introduction}

2-aminoethoxydiphenyl borate (2-apb) - is the chemical, originally introduced as an inhibitor of Inositol trisphosphate $\left(\mathrm{IP}_{3}\right)$-induced $\mathrm{Ca}^{2+}$ release [1]. Later, it was shown that 2-apb was able to modulate calcium currents without the participation of $\mathrm{IP}_{3}$-receptor [2]. In particular, 2-apb can affect store-operated calcium entry (SOCE) - the $\mathrm{Ca}^{2+}$ influx across the plasma membrane, which activated in response to depletion of intracellular $\mathrm{Ca}^{2+}$ stores in the endoplasmic reticulum [5, 6]. It has been found that 2-apb regulates the ion channels involved in the formation of calcium currents from the Transient receptor potential [5,6] and Calcium release activated channels [7] families, uncouples gap junctions $[8,9,10]$, and other. The 2-apb target depends on the taken concentration and the object of study.

Changes in the cell calcium concentration are important for the heart functioning both in normal conditions and in many physiological disorders, for example, in ischemia/reperfusion injury (IRI). IRI - is the condition in which the resumption of perfusion of the heart after ischemia does not lead to the restoration of its normal functioning, but, conversely, to aggravate the consequences of ischemic effects [11]. This phenomenon is interesting from the point of view of both practical medicine and scientific theory. The effect of IRI is largely due to the effect of hypoxia/reoxygenation (H/R) injury,
\end{abstract}


and the main causes of disturbances in the functioning of the heart and blood vessels are considered to be increased calcium overload and the formation of reactive oxygen species (ROS) [11].

The purpose of the presented research was to study the effect of 2-apb on the myocardial electrical conductivity and the rhythm of contraction of the isolated rat heart with using the multielectrode mapping method, as well as on the change in coronary blood flow (CBF) under H/R conditions.

\section{Material and methods}

All experimental protocols in this study were approved by the Bioethics Committee of Nizhny Novgorod State Medical Academy, and experiments were carried out according to Act 708n (23.08.2010) of the Russian Federation National Ministry of Public Health, which states the rules of laboratory practice for the care and use of laboratory animals, and the Council Directive 2010/63EU of the European Parliament (September, 22, 2010) on the protection of animals used for scientific purposes.

Wistar rats weighing 200-250 g were anesthetized (Zoletil 100, Virbac Sante Animale, 35 $\mathrm{mg} / \mathrm{kg}$, IP), then isolated hearts underwent retrograde perfusion according to the Langendorff method with Krebs-Henseleit solution ( $\mathrm{sKH}$ ): $\mathrm{NaCl} 118, \mathrm{KCl} 4.7, \mathrm{CaCl}_{2} 2, \mathrm{MgSO}_{4} 1.2, \mathrm{KH}_{2} \mathrm{PO}_{4} 1.2, \mathrm{NaHCO}_{3}$ 20, glucose $10 \mathrm{mmol} / \mathrm{L}$; pH $7.3-7.4$; at a temperature of $37 \mathrm{C}^{\circ}$; under a pressure of $80 \mathrm{~mm}$ of water column; saturated with carbogen $\left(95 \% \mathrm{O}_{2}\right.$ and $\left.5 \% \mathrm{CO}_{2}\right)$. 2-apb (Sigma, USA) was diluted in sKH (sKH+2-apb), $10 \mu \mathrm{mol} / \mathrm{L}$. H/R conditions were simulated by perfusion the heart with carbogen-free $\mathrm{sKH}$ followed by switching the perfusion to the $\mathrm{sKH}$ which was saturated with carbogen. The experimental protocol is presented in table 1.

Table 1

The experimental protocol

\begin{tabular}{|c|c|c|}
\hline The experimental groups & $\begin{array}{l}\text { The first phase of the } \\
\text { experiment }\end{array}$ & $\begin{array}{c}\text { The second phase of the } \\
\text { experiment }\end{array}$ \\
\hline «Control» (standard perfusion), $\mathrm{n}=10$ & sKH, normoxia (10 min) & sKH, normoxia (10 min) \\
\hline $\begin{array}{l}\text { «H/R» (perfusion with carbogen-free } \mathrm{sKH} \text { on the first phase of the } \\
\text { experiment), } \mathrm{n}=10\end{array}$ & sKH, hypoxia (10 min) & sKH, normoxia (10 min) \\
\hline $\begin{array}{l}\text { «2-apb» (perfusion with } \mathrm{sKH}+2 \text {-apb on the first phase of the } \\
\text { experiment), } \mathrm{n}=10\end{array}$ & 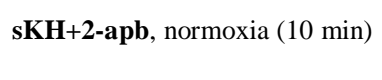 & sKH, normoxia (10 min) \\
\hline $\begin{array}{l}\ll 2-\mathrm{apb}+\mathrm{H} / \mathrm{R} »(\text { perfusion with carbogen-free } \mathrm{sKH}+2 \text {-apb on the first } \\
\text { phase of the experiment), } \mathrm{n}=10\end{array}$ & $\mathbf{s K H}+2$-apb, hypoxia (10 min) & sKH, normoxia (10 min) \\
\hline
\end{tabular}

Registration of the electrical activity of the hearts was performed from the surface of the left ventricle with using the flexible multi-electrode arrays MEAFlex72 (Multichannel systems, Germany) (Fig. 1, A, B). The electrical signals recorded from the electrodes were amplified, filtered, and digitized using the corresponding devices: MPA 32I preamplifier, differential filter amplifier FA64I and the data acquisition system with analog-to-digital converter USB-ME 128-System (Multichannel systems, Germany). Recorded electrical signals were visualized and analyzed with help of software applications Cardio2D and Cardio2D ${ }^{+}$(Multichannel systems, Germany) (Fig. 1, C, D, E).

The sufficient amount and configuration of the electrodes in the arrays allowed us to evaluate the value of the local activation times delay (LATD) between two selected electrodes on the epicardial surface. LATD is inversely proportional to the electrical conductivity of the myocardium. The electrodes for assessing LATD were selected based on the isochronal maps constructed in the Cardio2 $\mathrm{D}^{+}$program (Fig. $1 \mathrm{C}$ ). Myocardium is characterized by anisotropy - different conductivity of the electrical signal depending on the direction (in the longitudinal direction it is higher than in the transverse) [13]. It is generally accepted that anisotropy is due to the elongated shape of cardiomyocytes and the difference in the amount of gap junctions between the lateral surfaces of cardiomyocytes and intercalated discs [14]. In this work the sinus rhythm of the heart was investigated, 
the electrical stimulation was not applied. That's why the electrical propagation pattern hadn't ellipsoid shape because epicardial activity was affected by transmural propagation and Purkinje conduction. But still we could select the one pair of the electrodes with the longest value of LATD within one wavefront, and these values was considered as the value of the transverse conduction of the electrical excitation (Fig. 1, D, H4 and H5 electrodes). By this way, we evaluated the change in the duration of the transverse conduction in the myocardium for each heart, depending on the time and conditions of the experiment. The activation times at the electrodes were determined as the maximum downslope of the value of the field potential. It was problematically to assess the value of LATD during fibrillation because of inability to correctly determine activation times (Fig. 1, E).

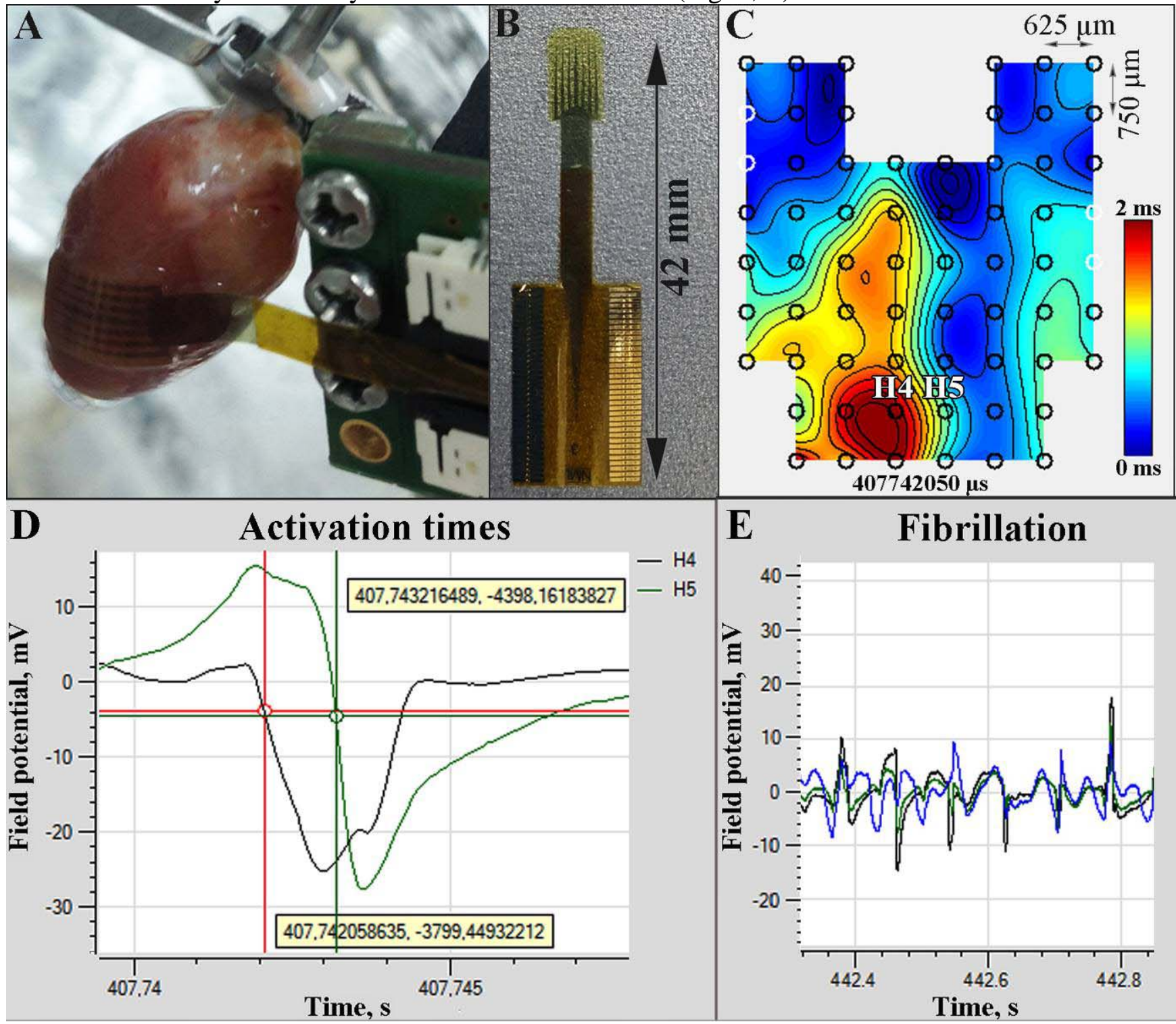

Fig. 1. Registration of the electrical activity of the isolated rat heart: A - superposition of the multi-electrode array on the surface of the left ventricle; B - multi-electrode array MEAFlex72; C isochronal maps (isochrone $=100 \mathrm{mV}$ ) constructed by the local activation times, which were detected on the electrodes (black circles), electrodes with no local time detected are marked by the white circles; H4 and H5 - is the selected pair of the electrodes for determining LATD; D - the local activation times of the $\mathrm{H} 4$ and $\mathrm{H} 5$ electrodes corresponding to the maximum downslope of the value of the field potential (y axis) over time (x axis); E - the example of the recording of field potentials from several electrodes during fibrillation 
Also, heart rate $(\mathrm{HR})$ and coefficient of heart rate variability $\left(\mathrm{CV}_{\mathrm{HR}}\right)$ were analyzed as the parameters of the electrical activity of the heart. $\mathrm{CV}_{\mathrm{HR}}(\%)=100 *$ standard deviation/average value of interbeat interval (IBI).

The volume of CBF ( $\mathrm{ml} / \mathrm{min}$ ) was measured as an indicator of the condition of the blood vessels of the heart.

Changes in the percentage of the values of LATD, HR and CBF were evaluated relative to the last minute of the phase of adaptation of the heart carried out under standard perfusion conditions for 10 minutes before the start of the experiment.

Statistical analysis was performed with GraphPad Prism 6 software (GraphPad Software, USA) using the Shapiro-Wilk test and the Friedman test for repeated measures $(p<0.05)$.

\section{Results and discussions}

\section{Local activation times delay}

«Control». In the control group LATD on the left ventricle surface stayed stable and was equal to $1.2 \pm 0.5 \mathrm{msec}$ (Fig. 2, A).

«H/R». Hypoxia didn't influence on the LATD values, but towards the end of the reoxygenation phase LATD was increased by $72.8 \pm 9.4 \%$ (Fig. 2, B). A decrease in electrical conductivity during reperfusion has also been shown in rat cardiomyocytes [15].

«2-apb». After seven to nine minutes of perfusion with $\mathrm{sKH}+2$-apb heart fibrillation was occurred. And two-seven-fold increase in LATD corresponded to the development of this condition (Fig. 2, C). Slowed myocardial conduction velocity is associated with the possibility of occurrence of re-entrant excitation, predisposing to cardiac arrhythmia [16]. The signals from electrodes underwent significant distortion, that's why mostly it was impossible to identify LATD values between them. On the second phase of the experiment, after switching the perfusion to standard sKH, fibrillation had stopped on average by the fourth minute. Changes in LATD after the period of fibrillation in different hearts were not of a general nature.

Fibrillation of isolated rat hearts caused by using $2-a p b(C=22 \mu \mathrm{mol} / \mathrm{L})$ was also observed by the other researchers [17]. In our work, heart fibrillation was observed with 2-apb in sKH at a concentration of $10 \mu \mathrm{mol}$. At a concentration of $10 \mu \mathrm{mol} / \mathrm{L} 2$-apb was used by other authors, for example, as an inhibitor or blocker of Transient receptor potential canonical 1 ( $\mathrm{TRPC}_{1}$ ) channels [5], $\mathrm{IP}_{3}$ receptors $[18,19]$ and SOCE [20]. And this prevented an increase in $\left[\mathrm{Ca}^{2+}\right]_{\text {in }}$ in response to different kinds of biochemical effects in cardiomyocytes [5, 18], in vascular smooth muscle cells [20] and fibroblasts [19]. Thus, the cause of fibrillation in our study could be the mechanisms associated with the effect of 2-apb on the concentration of $\mathrm{Ca}^{2+}$ ions in heart cells.

For different types of cells, 2-apb has been shown to inhibit or block Cx40, Cx43, Cx45 isoforms of connexins, which are expressed in the heart [10] in concentrations in the range of $1-100 \mu \mathrm{mol} / \mathrm{L}[8$, $9,10]$. Since the connexin inhibition by 2 -apb is caused in a dose-dependent manner, we can assume that in our work, using of 2-apb at a concentration of $10 \mu \mathrm{mol} / \mathrm{L}$ could leads to uncoupling of gap junctions, and this resulted in increase in the values of LATD and fibrillation because of electrical conduction slowing [21].

«2-apb+H/R». In this study, it was shown that 2-apb caused fibrillation under the normoxia, but not under the hypoxia. During perfusion with sKH+2-apb in hypoxic conditions LATD increased by $18.1-310.5 \%$ (Fig. 2, D). And after resumption of normal perfusion conditions, there were no differences in the LATD changes $(\mathrm{p}<0,05)$.

If $2-\mathrm{apb}$ at a concentration of $10 \mu \mathrm{mol} / \mathrm{L}$ decreases $\left[\mathrm{Ca}^{2+}\right]_{\text {in }}[5,18-20]$, while under hypoxia $\left[\mathrm{Ca}^{2+}\right]_{\text {in }}$ increases [12], then this mutually exclusive interaction of 2-apb and the hypoxia effect could prevent the development of fibrillation on the one hand, and changes in H/R observed with hypoxia on the other. 
It was shown that connexins are dephosphorylated during hypoxia [22]. This could disrupt their binding to 2-apb and thus prevent fibrillation. According to some reports, 2-apb is able to bind directly to ROS [23], which are formed during hypoxia [12]. Thus, the concentration of the blocker entering the heart could decrease and become insufficient for fibrillation to occurrence.
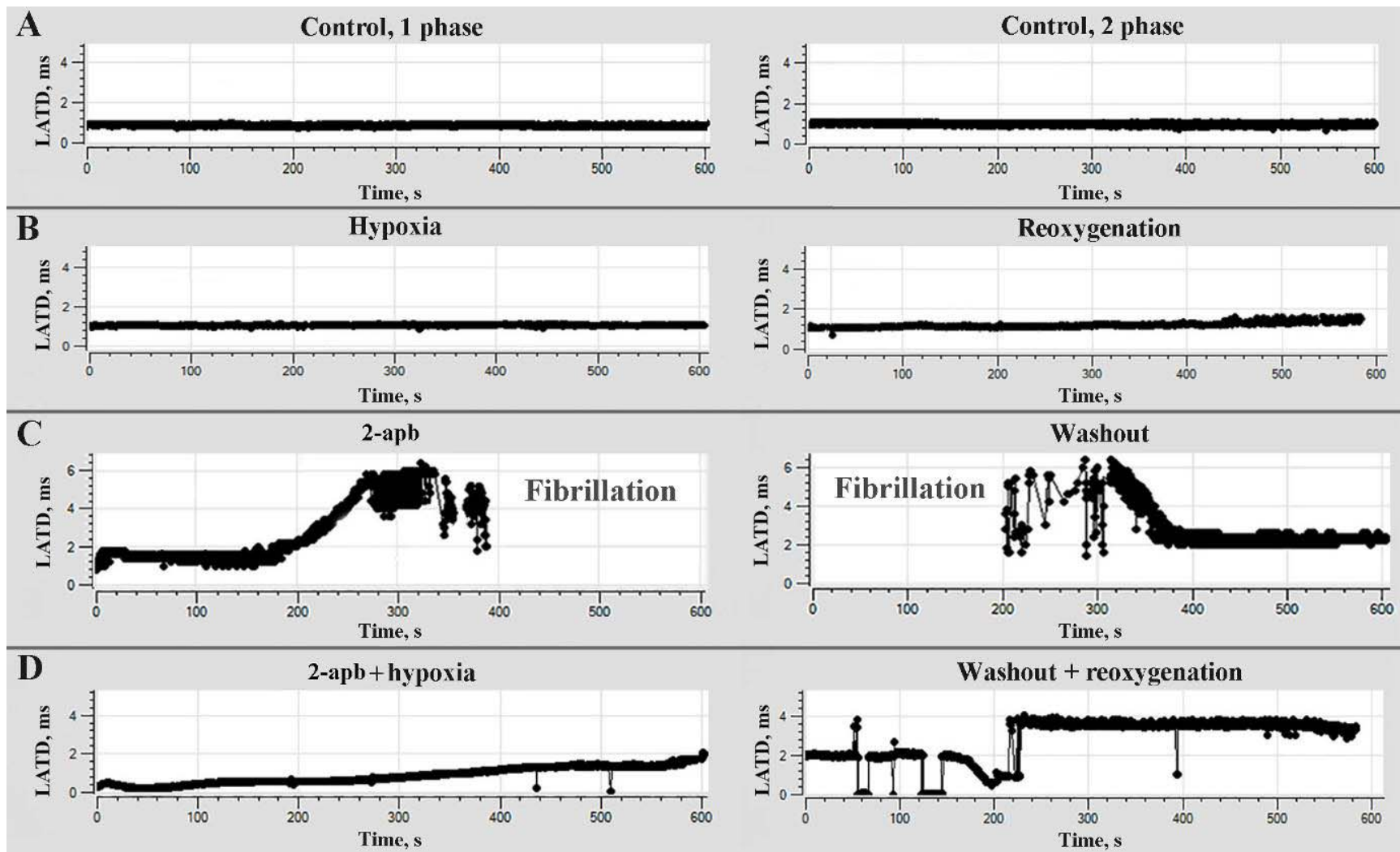

Fig. 2. Changes of the values of LATD (y axis) relative to time (x axis) on the examples of the hearts from different experimental groups: $\mathbf{A}-$ - $C o n t r o l » ~(n=10)$, perfusion with standard sKH in normoxia during two experimental phases; $\mathbf{B}-\ll \mathrm{H} / \mathrm{R} \gg(\mathrm{n}=10)$, perfusion with carbogen-free $\mathrm{KHH}$ on the first and with carbogen saturated sKH on the second (reoxygenation) experimental phases; $\mathbf{C}-\ll 2$ apb» $(\mathrm{n}=10)$, perfusion with $\mathrm{sKH}+2-\mathrm{apb}, 10 \mu \mathrm{mol} / \mathrm{L}$, on the first and with standard $\mathrm{sKH}$ on the second (washout) experimental phases; $\mathbf{D}-\ll 2-\mathrm{apb}+\mathrm{H} / \mathrm{R} »(\mathrm{n}=10)$, perfusion with carbogen-free $\mathrm{sKH}+2-\mathrm{apb}$, $10 \mu \mathrm{mol} / \mathrm{L}$, on the first and with carbogen saturated standard $\mathrm{sKH}$ on the second experimental phases

\section{Heart rate and heart rate variability}

«Control». $\mathrm{HR}$ and $\mathrm{CV}_{\mathrm{HR}}$ did not change during the experiment $(\mathrm{p}<0.05)$ and were $246.7 \pm 36.8$ bpm (Fig. 3, A) and 1.9 $\pm 1.2 \%$ (Fig. 4, A), respectively.

«/R». Under hypoxia, after 100-200 seconds, HR increased up to $132.4 \%$ in some hearts. Whith reoxygenation the fall of HR to $81.3 \pm 2.1 \%$ was observed (Fig. 2B). During both phases of the experiment rhythm disturbances occurred (Fig. 3, B). Value of $\mathrm{CV}_{\mathrm{HR}}$ in some hearts reached $12.7 \%$. The lack of oxygen leads to accumulation of $\mathrm{Na}^{+}$and $\mathrm{Ca}^{2+}$ ions in the cells due to the inhibition of ATP-dependent transporters, and reoxygenation causes calcium overload [12], which could cause such a picture of $\mathrm{HR}$ and $\mathrm{CV}_{\mathrm{HR}}$ changes.

«2-apb». Significant increase of $\mathrm{HR}$ (up to three times) and $\mathrm{CV}_{\mathrm{HR}}$ (up to 34\%) preceded fibrillation (Fig. 3, C; Fig. 4, C). After fibrillation HR stayed increased (370.1 $159 \%$ ) and declined later (Fig. 3, C). $\mathrm{CV}_{\mathrm{HR}}$ was high and reached up to $14.7 \%$ in some hearts after fibrillation on the second phase of the experiment (Fig. 4, C). This could be due to the effect of 2-apb on ionic concentrations in the sinus node pacemaker cells. 
«2-apb+H/R». There were no changes in the HR value $(\mathrm{p}<0.05)$ in these conditions (Fig. 3, D). $\mathrm{CV}_{\mathrm{HR}}$ reached a value of $18.33 \%$ in some hearts on the first phase of the experiment, and by the end of the second experimental phase ranged from $0.26 \%$ to $8.6 \%$ (Fig. 3D). It has been demonstrated that pharmacological inhibition of SOCE, which was shown for 2-apb [20], prevents calcium overload at H/ R [24]. And this could offset the effect of hypoxia on HB in these conditions.

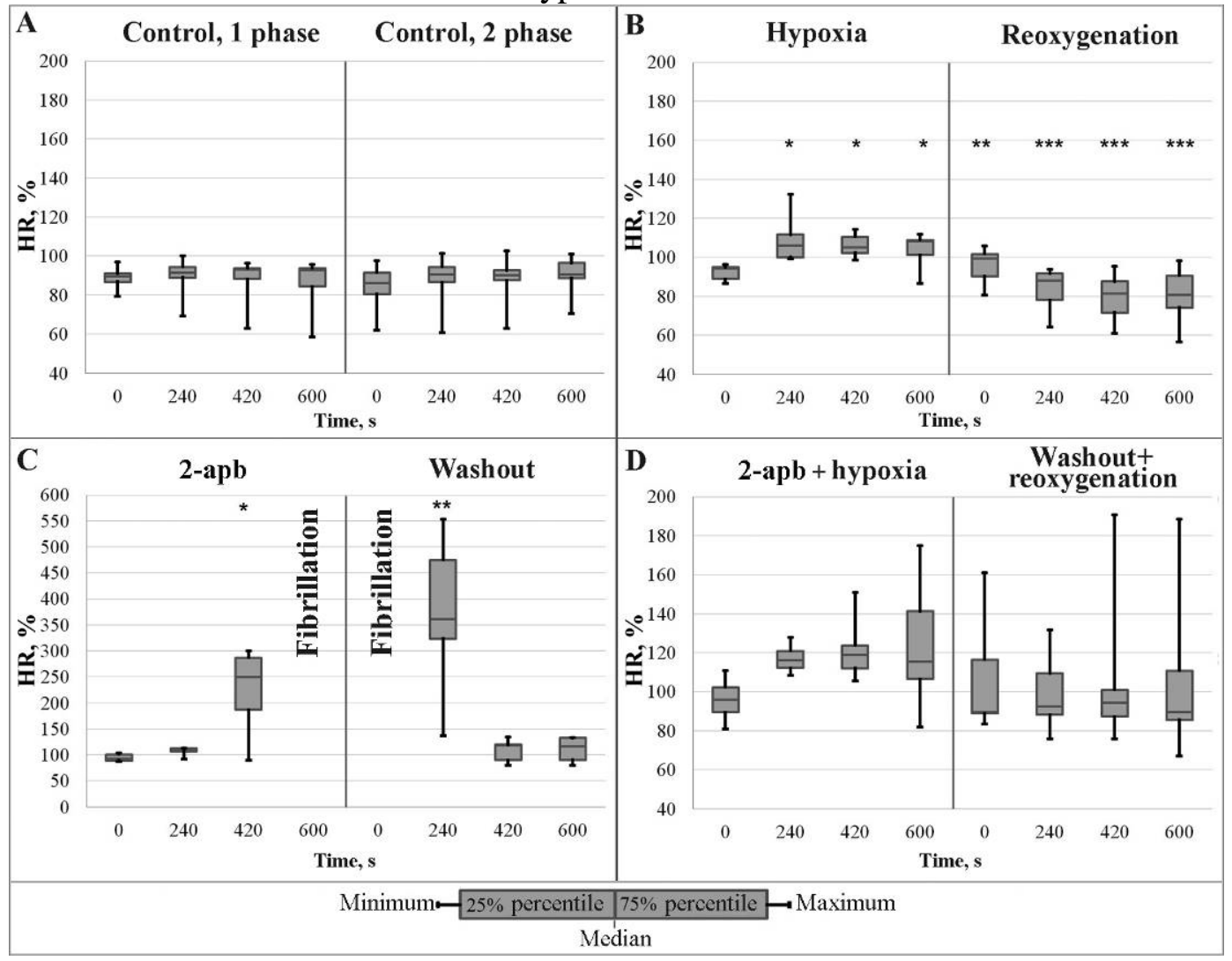

Fig. 3. Changes of the values of HR in percentage (y axis) relative to time (x axis) in the experimental groups: A - «Control» $(\mathrm{n}=10)$, perfusion with standard $\mathrm{sKH}$ in normoxia during two experimental phases; $\mathbf{B}-\langle\mathrm{H} / \mathrm{R} »(\mathrm{n}=10)$, perfusion with carbogen-free $\mathrm{sKH}$ on the first and with carbogen saturated sKH on the second (reoxygenation) experimental phases; $\mathbf{C}-\ll 2$-apb» $(\mathrm{n}=10)$, perfusion with $\mathrm{sKH}+2-\mathrm{apb}, 10 \mu \mathrm{mol} / \mathrm{L}$, on the first and with standard $\mathrm{sKH}$ on the second (washout) experimental phases; D - «2-apb+H/R» $(n=10)$, perfusion with carbogen-free $\mathrm{sKH}+2-\mathrm{apb}, 10 \mu \mathrm{mol} / \mathrm{L}$, on the first and with carbogen saturated standard $\mathrm{SKH}$ on the second experimental phases. *, **, *** the presence of statistically significant differences in the values of HR from the last minute of adaptation (not shown on the graph) taken as $100 \%$ according to the Friedman test for repeated measures $(\mathrm{p}<0.05)$ 

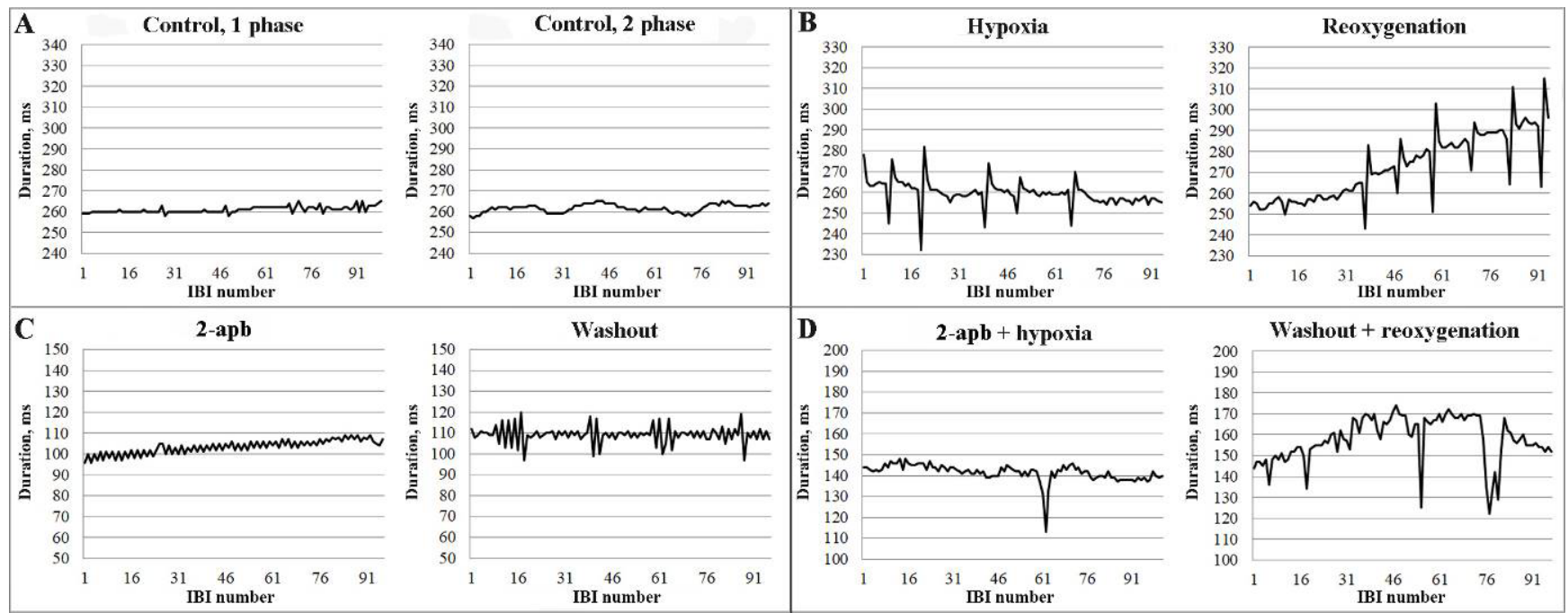

Fig. 4. The sequences of IBIs (the values of the time duration of IBIs - y axis; numbers of IBIs $\mathrm{x}$ axis) taken on the third and seventh minutes of the first and second phases of the experiment, respectively on the examples of the hearts from different experimental groups: $\mathbf{A}-$ «Control» $(\mathrm{n}=10)$, perfusion with standard sKH in normoxia during two experimental phases; $B-\ll H / R »(n=10)$, perfusion with carbogen-free sKH on the first and with carbogen saturated $\mathrm{sKH}$ on the second (reoxygenation) experimental phases; $\mathbf{C}-\ll 2-a p b »(n=10)$, perfusion with sKH+2-apb, $10 \mu \mathrm{mol} / \mathrm{L}$, on the first and with standard sKH on the second (washout) experimental phases; D - «2-apb+H/R» $(n=10)$, perfusion with carbogen-free $\mathrm{sKH}+2-\mathrm{apb}, 10 \mu \mathrm{mol} / \mathrm{L}$, on the first and with carbogen saturated standard sKH on the second experimental phases

\section{The volume of coronary blood flow}

«Control». Under standard conditions of perfusion CBF of isolated hearts gradually decreased on average by $29.3 \pm 20.4 \%$ by the end of the experiment (Fig. 5 , A).

«H/R». Under hypoxia toward to the end of the first experimental phase the value of $\mathrm{CBF}$ increased an average by $116.6 \pm 40.2 \%$. Presumably, this was due to the vasodilating effect of NO, which is secreted by endothelial cells during hypoxia [19]. Reoxygenation provoked decrease of CBF value to $69.2 \pm 32.6 \%$ (Fig. 5, B).

«2-apb». In response to the presence of 2-apb CBF was risen during the first five minutes, as maximum of $21 \%$. And then $\mathrm{CBF}$ returned to the initial values without changing $(\mathrm{p}<0.05)$ until the end of the experiment (Fig. 5, C), in contrast to the decrease in CBF observed under normal conditions of perfusion (Fig. 5, A). The vasodilating effect of 2-apb has been shown by other authors [26]. Disruption of the normal condition of the vessels also can cause the fibrillation [27].

«2-apb+H/R». There were no statistically significant changes of CBF in the in this experimental group ( $\mathrm{p}<0.05$ ). Namely, an increase of CBF caused by hypoxia did not occur in the presence of 2 -apb, as well as the $\mathrm{CBF}$ decline during reoxygenation, which was observed during 2-apb-free sKH perfusion (Fig. 5, B, D). 


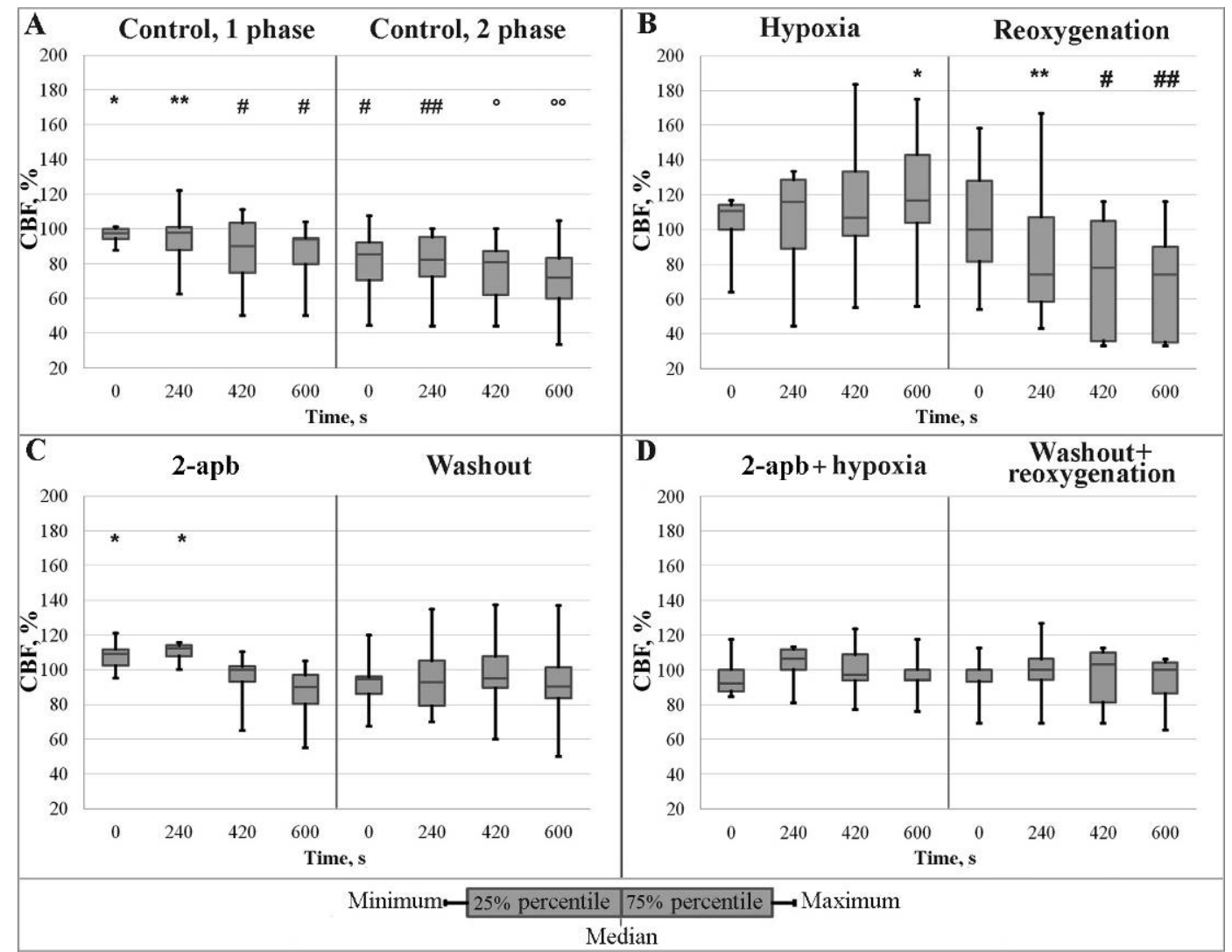

Fig. 5. Changes of the values of $\mathrm{CBF}$ in percentage (y axis) relative to time ( $\mathrm{x}$ axis) in the experimental groups: A - «Control» $(\mathrm{n}=10)$, perfusion with standard $\mathrm{sKH}$ in normoxia during two experimental phases; $\mathbf{B}-\langle\mathrm{H} / \mathrm{R} »(\mathrm{n}=10)$, perfusion with carbogen-free $\mathrm{sKH}$ on the first and with carbogen saturated sKH on the second (reoxygenation) experimental phases; $\mathbf{C}-\ll 2$-apb» $(\mathrm{n}=10)$, perfusion with $\mathrm{sKH}+2-\mathrm{apb}, 10 \mu \mathrm{mol} / \mathrm{L}$, on the first and with standard $\mathrm{sKH}$ on the second (washout) experimental phases; $\mathbf{D}-\ll 2-\mathrm{apb}+\mathrm{H} / \mathrm{R} »(\mathrm{n}=10)$, perfusion with carbogen-free $\mathrm{sKH}+2-\mathrm{apb}, 10 \mu \mathrm{mol} / \mathrm{L}$, on the first and with carbogen saturated standard sKH on the second experimental phases. *, **, \#, \#\#, $\circ,{ }^{\circ}$ - the presence of statistically significant differences in the values of CBF from the last minute of adaptation (not shown on the graph) taken as $100 \%$ according to the Friedman test for repeated measures $(\mathrm{p}<0.05)$

\section{Conclusions}

As a result of the study, it was shown that 2-apb affects the parameters of electrical activity and the conditions of the vessels of the isolated rat heart. In particular, perfusion of the heart with a solution containing 2-apb provides:

- the slowing of the myocardial conduction velocity and the development of heart fibrillation, which was observed with normoxia, but not with hypoxia;

- the increase in HR and prevent the decline of this parameter, which was observed under reoxygenation;

- the increase in HR variability, which was more noticeable with in normoxic conditions than under $\mathrm{H} / \mathrm{R}$;

- the dilation of coronary vessels and stabilization of $\mathrm{CBF}$, while under hypoxia this parameter markedly increased, and during normoxia and reoxygenation decreased.

The effect of 2-apb can be explained by the influence of this compound on the $\left[\mathrm{Ca}^{2+}\right]_{\text {in }}$ of the heart and blood vessels due to the possible regulation of TRPC ${ }_{1}$ channels, $\mathrm{IP}_{3}$ receptors, and SOCE $[5$, $18-20]$ and by the ability to disconnect gap junctions [8-10]. Changes in $\left[\mathrm{Ca}^{2+}\right]_{\text {in }}$ under the action of 2- 
apb could affect the duration of the action potential of pacemaker cells responsible for the rhythm of heart contractions, which in this paper was evaluated by $\mathrm{HR}$ and $\mathrm{CV}_{\mathrm{HR}}$ parameters. Probably changes in $\left[\mathrm{Ca}^{2+}\right]_{\text {in }}$ and uncoupling of gap junctions could influence on the electrical conduction in the myocardium. It can be concluded from the observed decrease in the value of LATD, which was analyzed by the multi-electrode mapping of the heart. The 2-apb-induced changes in $\left[\mathrm{Ca}^{2+}\right]$ in vascular cells were presumably due to the SOCE mechanism and could cause vasodilation, as CBF analysis have shown.

Despite the fact that under normoxia 2-apb causes arrhythmias and fibrillation of the isolated heart, it should be noted its stabilizing effect on CBF under H/R conditions.

For the understanding the mechanism of action of 2-apb on the cardiovascular system, further studies of its properties are required.

\section{Acknowledgement}

This study was financially supported by the Russian Foundation for Basic Research within the framework of the project \#17-02-00467.

\section{Disclosure of conflict of interests}

None.

\section{References}

1. Maruyama T., Kanaji T., Nakade S., Kanno T., Mikoshiba K. 2APB, 2-aminoethoxydiphenyl borate, a membrane-penetrable modulator of $\mathrm{Ins}(1,4,5) \mathrm{P} 3$-induced $\mathrm{Ca}^{2+}$ release. J Biochem. 1997; 122(3): 498-505. doi: 10.1093/oxfordjournals.jbchem.a021780.

2. Dobrydneva Y., Blackmore P. 2-Aminoethoxydiphenyl borate directly inhibits store-operated calcium entry channels in human platelets. Mol Pharmacol. 2001; 60(3): 541-52.

3. Putney J. W. Jr. A model for receptor-regulated calcium entry. Cell Calcium. 1986; 7 (1): 112. doi.org/10.1016/0143-4160(86)90026-6.

4. Ambudkar I.S., de Souza L.B., Ong H.L. TRPC1, Orai1, and STIM1 in SOCE: Friends in tight spaces. Cell Calcium. 2017; 63: 33-9. doi: 10.1016/j.ceca.2016.12.009.

5. Kojima A., Kitagawa H., Omatsu-Kanbe M., Matsuura H., Nosaka S. Ca2+ paradox injury mediated through TRPC channels in mouse ventricular myocytes. Br J Pharmacol. 2010; 161(8): 173450. doi: 10.1111/j.1476-5381.2010.00986.x.

6. Hu H.Z., Gu Q., Wang C., Colton C.K., Tang J., Kinoshita-Kawada M., Lee L.Y., Wood J.D., Zhu M.X. 2-aminoethoxydiphenyl borate is a common activator of TRPV1, TRPV2, and TRPV3. J Biol Chem. 2004; 279(34): 35741-8. doi: 10.1074/jbc.M404164200.

7. Prakriya M., Lewis R.S. Potentiation and inhibition of $\mathrm{Ca} 2+$ release-activated $\mathrm{Ca} 2+$ channels by 2-aminoethyldiphenyl borate (2-APB) occurs independently of IP3 receptors. J Physiol. 2001; 536(Pt 1): 3-19. doi: 10.1111/j.1469-7793.2001.t01-1-00003.x.

8. Harks E.G., Camiña J.P., Peters P.H., Ypey D.L., Scheenen W.J., van Zoelen E.J., Theuvenet A.P. Besides affecting intracellular calcium signaling, 2-APB reversibly blocks gap junctional coupling in confluent monolayers, thereby allowing measurement of single-cell membrane currents in undissociated cells. FASEB J. 2003; 17(8): 941-3. doi: 10.1096/fj.02-0786fje.

9. Yang Y., Cao M.H., Wang Q., Yuan D.D., Li L., Tao L. The effects of 2aminoethoxydiphenyl borate and diphenylboronic anhydride on gap junctions composed of Connexin43 in $\mathrm{TM}_{4}$ sertoli cells. Biol Pharm Bull. 2011; 34(9): 1390-7. doi: 10.1248/bpb.34.1390.

10. Bai D., del Corsso C., Srinivas M., Spray D.C. Block of specific gap junction channel subtypes by 2-aminoethoxydiphenyl borate (2-APB). J Pharmacol Exp Ther. 2006; 319(3): 1452-8. doi: 10.1124/jpet.106.112045. 
11. Jennings R.B., Sommers H.M., Smyth G.A., Flack H.A., Linn H. Myocardial necrosis induced by temporary occlusion of a coronary artery in the dog. Arch Pathol. 1960; 70: 68-78.

12. Kalogeris T., Baines C.P., Krenz M., Korthuis R. J. Cell Biology of Ischemia/reperfusion Injury. Int Rev Cell Mol Biol. 2012; 298: 229-317. doi: 10.1016/B978-0-12-394309-5.00006-7.

13. Spach M.S., Miller W.T., Geselowitz D.B., Barr R.C., Kootsey J.M., Johnson E.A. The discontinuous nature of propagation in normal canine cardiac muscle. Evidence for recurrent discontinuities of intracellular resistance that affect the membrane currents. Circ Res. 1981; 48(1): 3954. doi: 10.1161/01.res.48.1.39.

14. Hoyt R.H., Cohen M.L., Saffitz J.E. Distribution and three-dimensional structure of intercellular junctions in canine myocardium. Circ Res. 1989; 64: 563-74. doi: 10.1161/01.res.64.3.563.

15. De Diego C., Pai R.K., Chen F., Xie L.H., De Leeuw J., Weiss J.N., Valderrábano M. Electrophysiological consequences of acute regional ischemia/reperfusion in neonatal rat ventricular $\begin{array}{llllll}\text { myocyte } & \text { monolayers. } & \text { Circulation. } & \text { 2008; } & 118 & \text { (23): }\end{array}$ 10.1161/CIRCULATIONAHA.108.789149.

16. King J.H., Huang C.L., Fraser J.A. Determinants of myocardial conduction velocity: implications for arrhythmogenesis. Front Physiol. 2013; 4: 154. doi: 10.3389/fphys.2013.00154.

17. Wang P., Umeda P.K., Sharifov O.F., Halloran B.A., Tabengwa E., Grenett H.E., Urthaler F., Wolkowicz P.E. Evidence that 2-aminoethoxydiphenyl borate provokes fibrillation in perfused rat hearts via voltage-independent calcium channels. Eur J Pharmacol. 2012; 681(1-3): 60-7. doi: 10.1016/j.ejphar.2012.01.045.

18. Wacker M.J., Kosloski L.M., Gilbert W.J.R., Touchberry C.D., Moore D.S., Kelly J.K., Brotto M., Orr J.A. Inhibition of thromboxane A2-Induced arrhythmias and intracellular calcium changes in cardiac myocytes by blockade of the inositol trisphosphate pathway. J Pharmacol Exp Ther. 2009; 331(3): 917-924. doi: 10.1124/jpet.109.157677.

19. Uhlén P., Burch P.M., Zito C.I., Estrada M., Ehrlich B.E., Bennett A.M. Gain-offunction/Noonan syndrome SHP-2/Ptpn11 mutants enhance calcium oscillations and impair NFAT signaling. Proc Natl Acad Sci U S A. 2006; 103(7): 2160-5. doi: 10.1073/pnas.0510876103.

20. Dale P., Head V., Dowling M.R., Taylor C.W. Selective inhibition of histamine-evoked Ca2+ signals by compartmentalized cAMP in human bronchial airway smooth muscle cells. Cell Calcium. 2018; 71: 53-64. doi: 10.1016/j.ceca.2017.12.002.

21. Severs N.J., Bruce A.F., Dupont E., Rothery S. Remodelling of gap junctions and connexin expression in diseased myocardium. Cardiovasc Res. 2008; 80(1):9-19. doi: 0.1093/cvr/cvn133.

22. Matsushita S., Kurihara H., Watanabe M., Okada T., Sakai T., Amano A. Alterations of phosphorylation state of connexin 43 during hypoxia and reoxygenation are associated with cardiac function. J Histochem Cytochem. 2006; 54(3): 343-53. doi: 10.1369/jhc.4A6611.2005.

23. Morihara H., Obana M., Tanaka S., Kawakatsu I., Tsuchiyama D., Mori S., Suizu H., Ishida A., Kimura R., Tsuchimochi I., Maeda M., Yoshimitsu T., Fujio Y., Nakayama H. 2aminoethoxydiphenyl borate provides an anti-oxidative effect and mediates cardioprotection during ischemia reperfusion in mice. PLoS One. 2017; 12 (12): e0189948 doi: 10.1371/journal.pone.0189948.

24. Potocnik S.J., Hill M.A. Pharmacological evidence for capacitative $\mathrm{Ca} 2+$ entry in cannulated and pressurized skeletal muscle arterioles. $\mathrm{Br}$ J Pharmacol. 2001; 134(2): 247-56. doi: 10.1038/sj.bjp.0704270.

25. Mahida S., Sacher F., Derval N., Berte B., Yamashita S., Hooks D., Denis A., Amraoui S., Hocini M., Haissaguerre M., Jais P. Science Linking Pulmonary Veins and Atrial Fibrillation. Arrhythm Electrophysiol Rev. 2015; 4(1): 40-3. doi: 10.15420/aer.2015.4.1.40.

26. Potocnik S.J., Hill M.A. Pharmacological evidence for capacitative $\mathrm{Ca} 2+$ entry in cannulated and pressurized skeletal muscle arterioles. Br J Pharmacol. 2001; 134(2): 247-56. doi: 10.1038/sj.bjp.0704270. 

not certified by peer review) is the author/funder. All rights reserved. No reuse allowed without permission.

27. Mahida S., Sacher F., Derval N., Berte B., Yamashita S., Hooks D., Denis A., Amraoui S., Hocini M., Haissaguerre M., Jais P. Science Linking Pulmonary Veins and Atrial Fibrillation. Arrhythm Electrophysiol Rev. 2015; 4(1): 40-3. doi: 10.15420/aer.2015.4.1.40. 


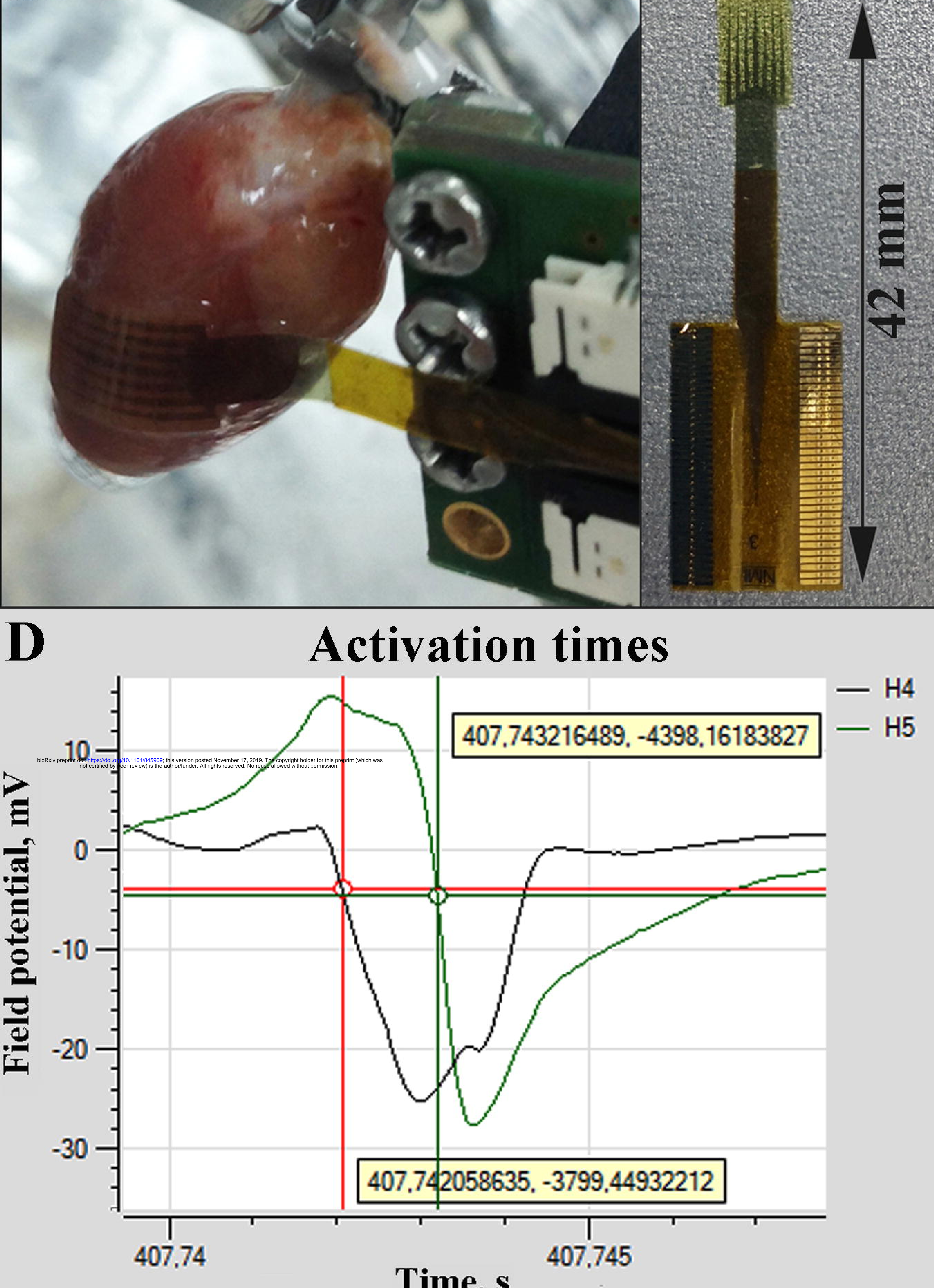

\section{E Fibrillation}

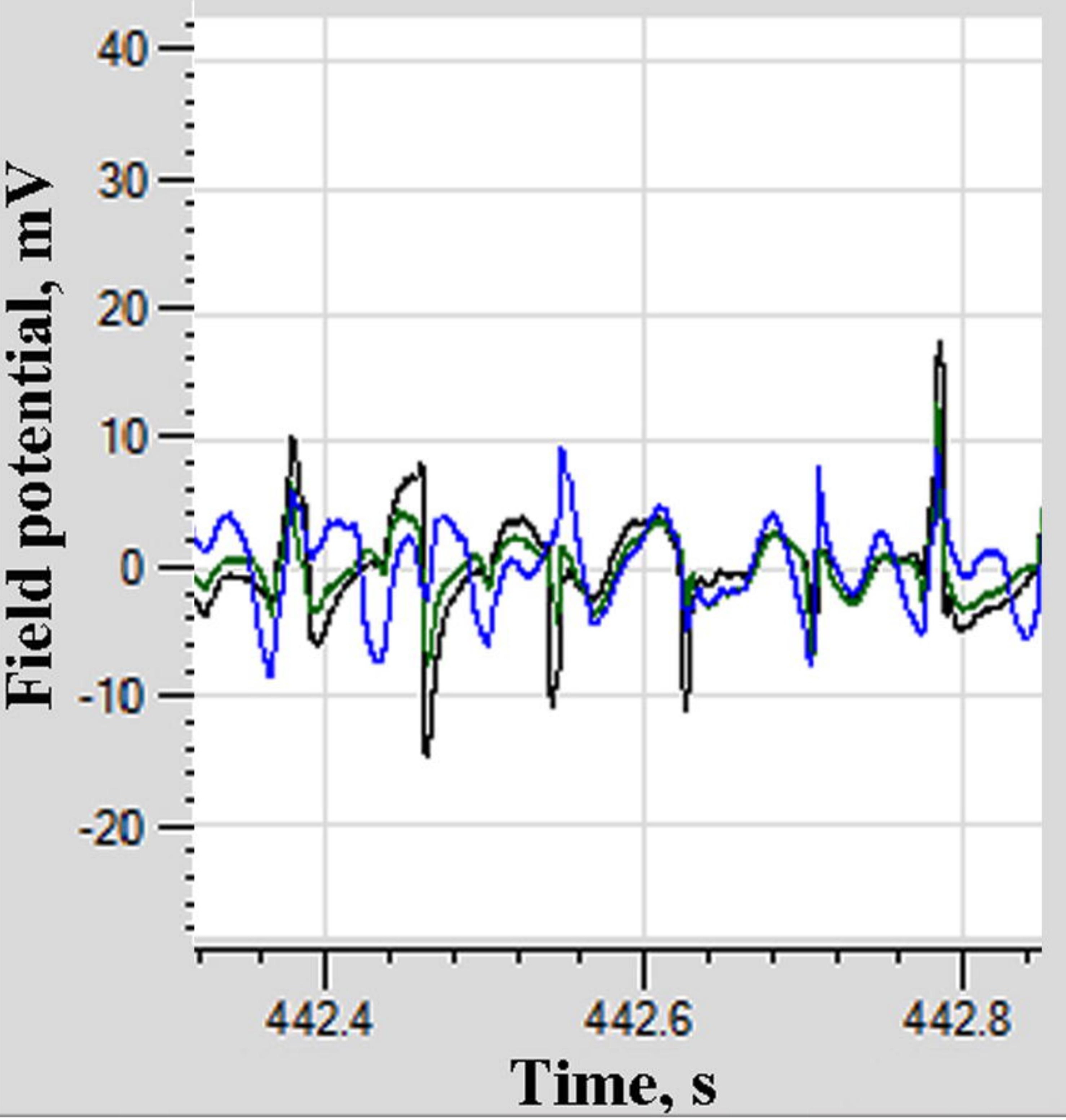


A

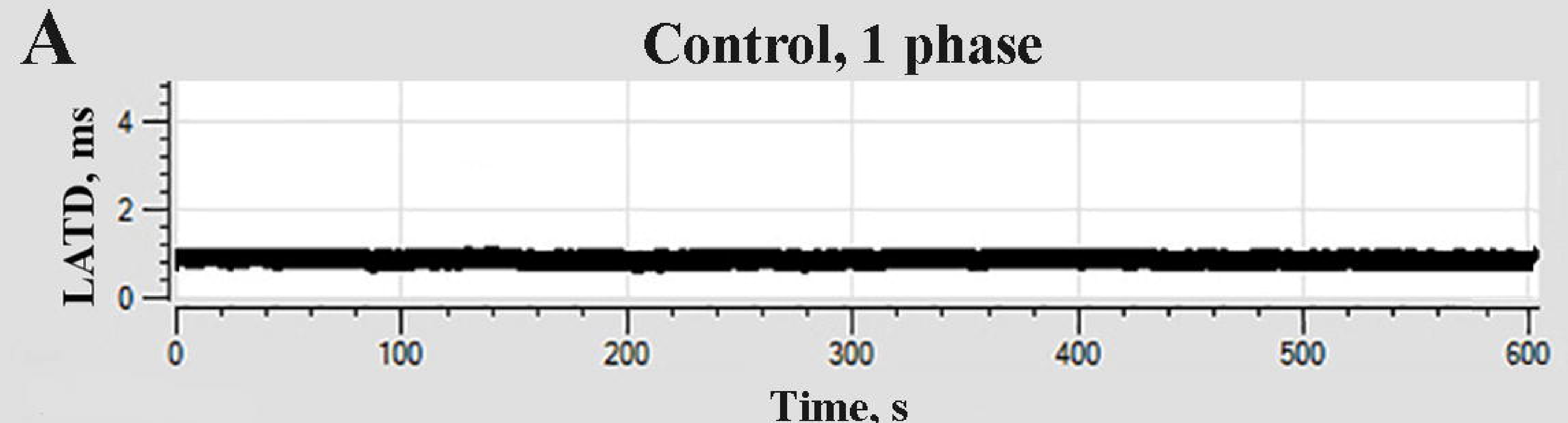

Typoxia

B

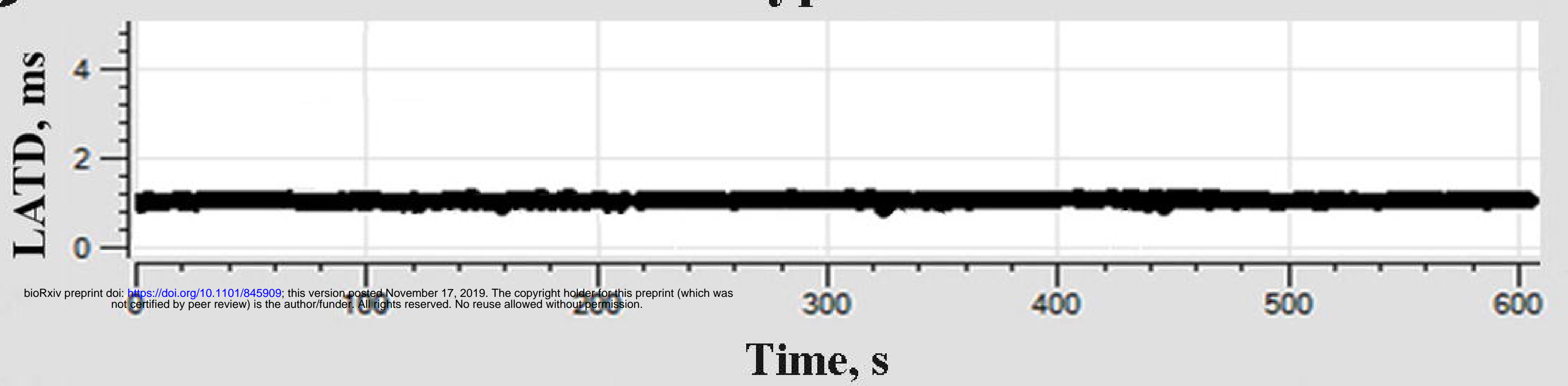

Time, $s$

C

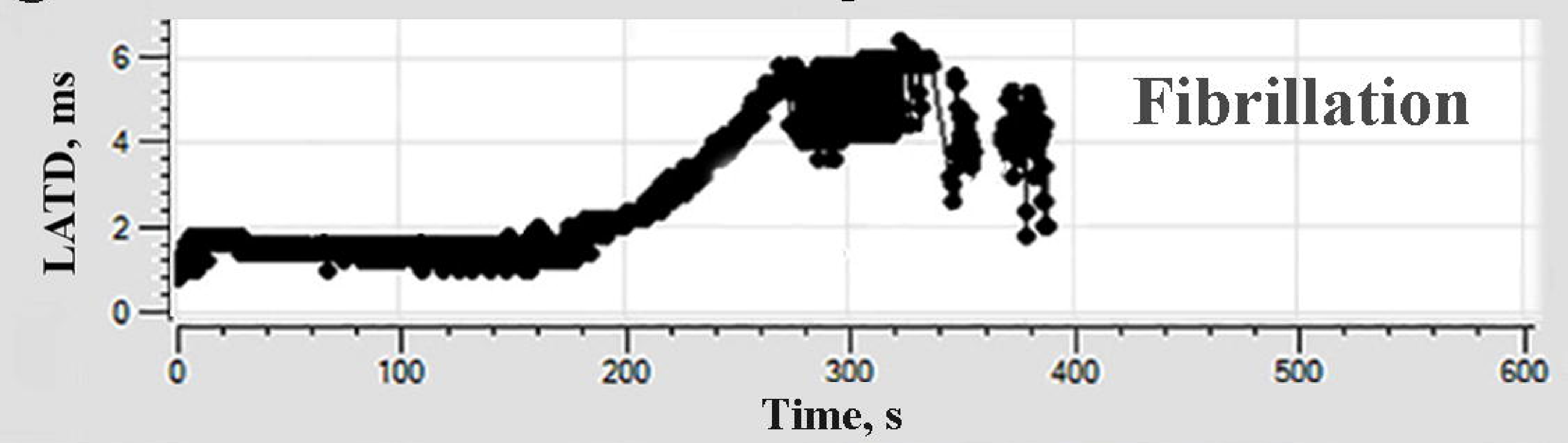

D

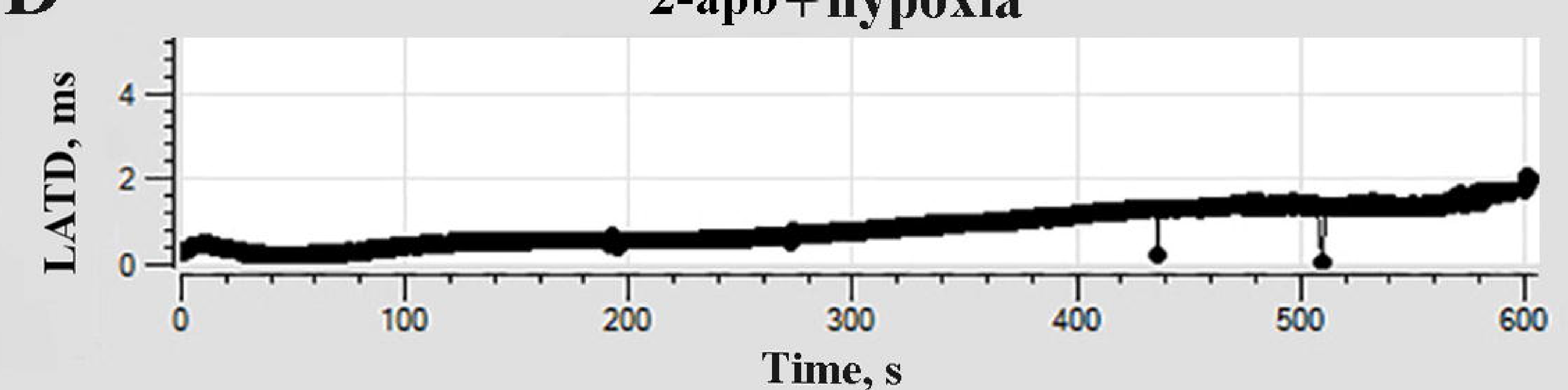

Control, 2 phase

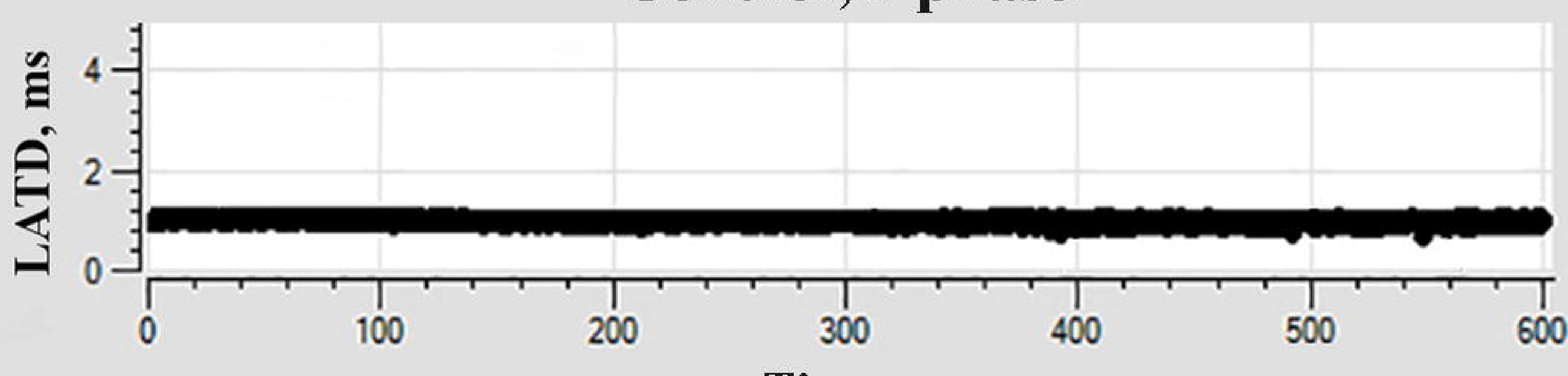

Time, $\mathrm{s}$

Reoxygenation

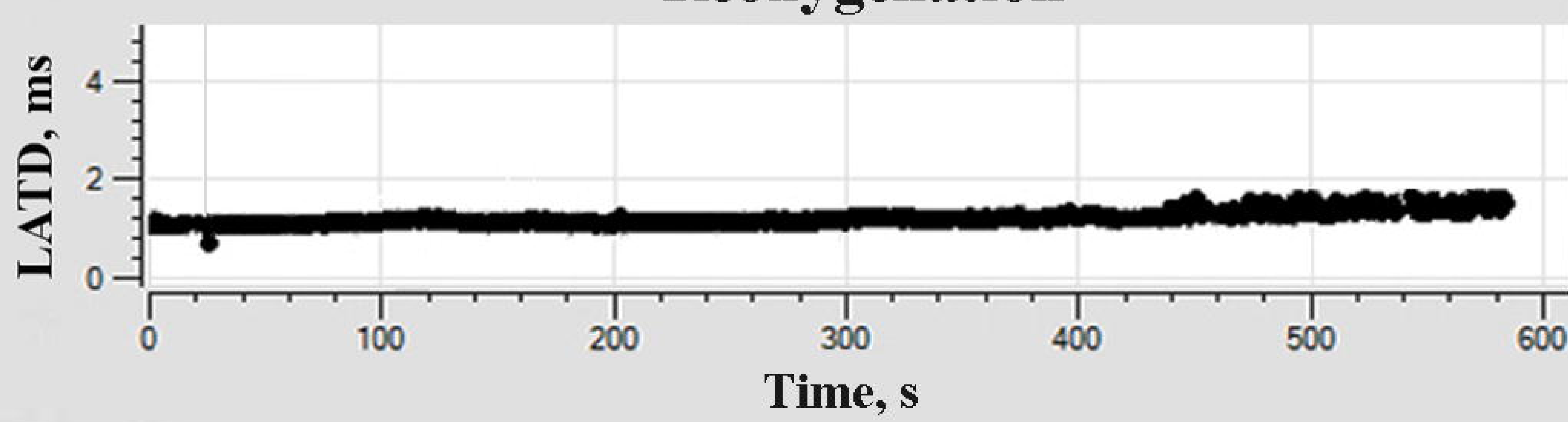

Washout

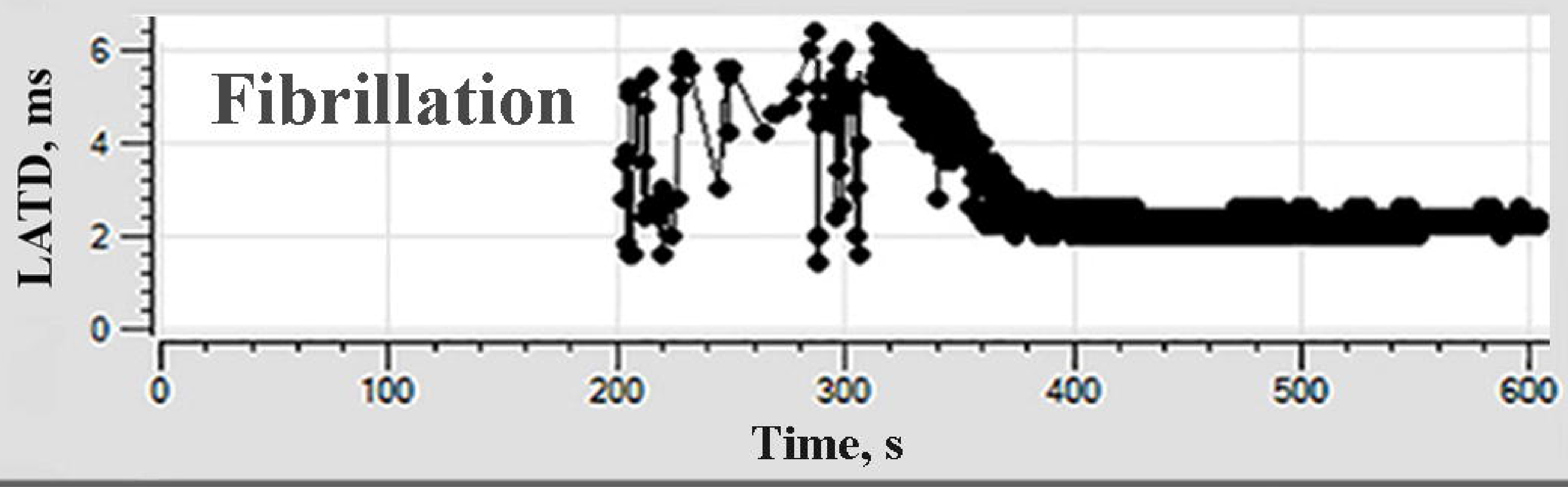

Washout + reoxygenation

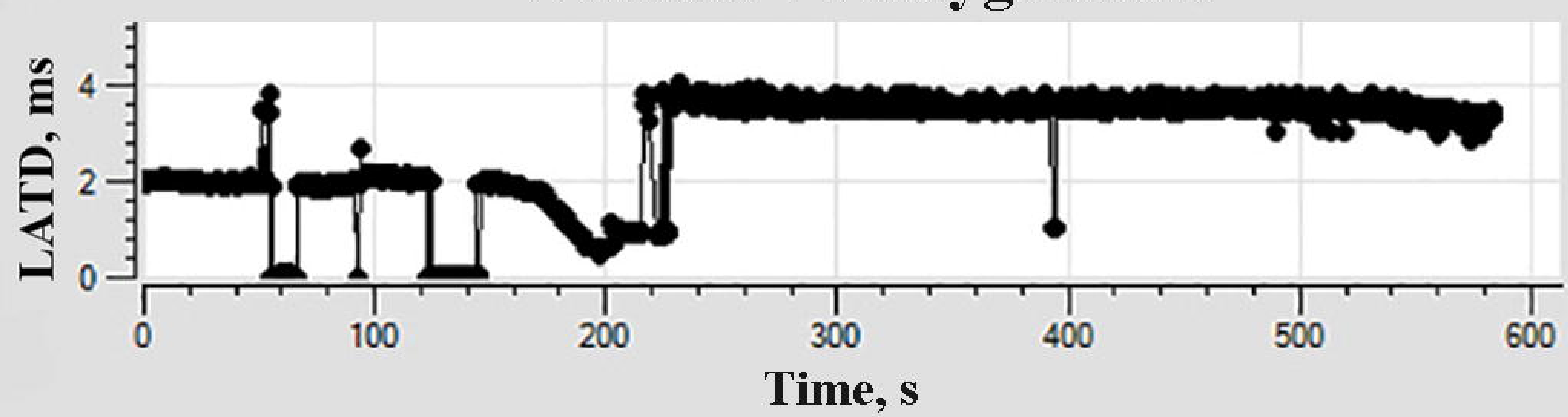


Control, 1 phase

Control, 2 phase

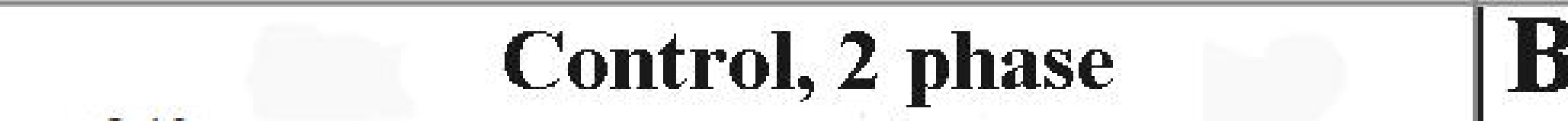

Hypoxia

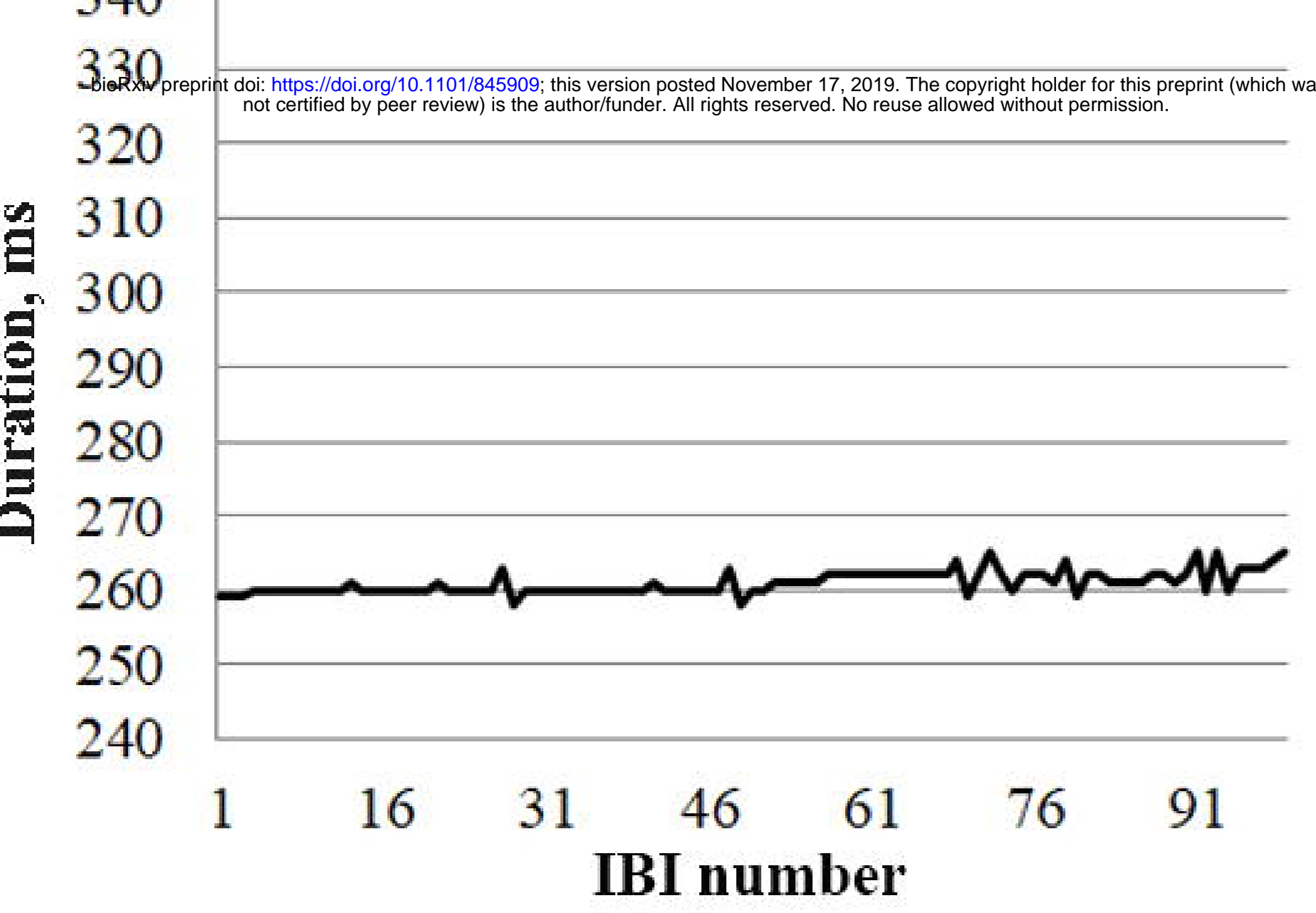

$\mathrm{C}$ IBI number

2-apb

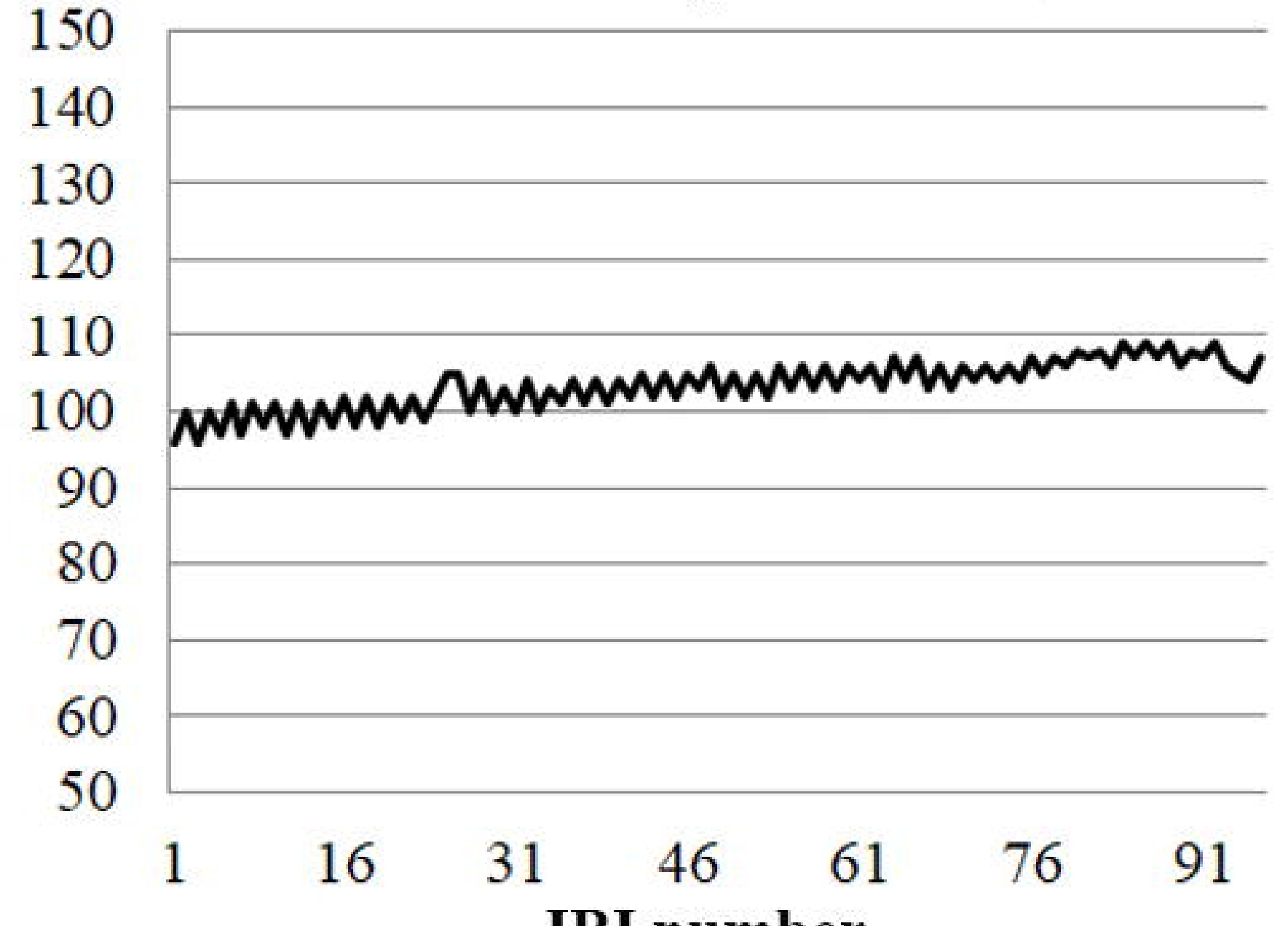
IBI number

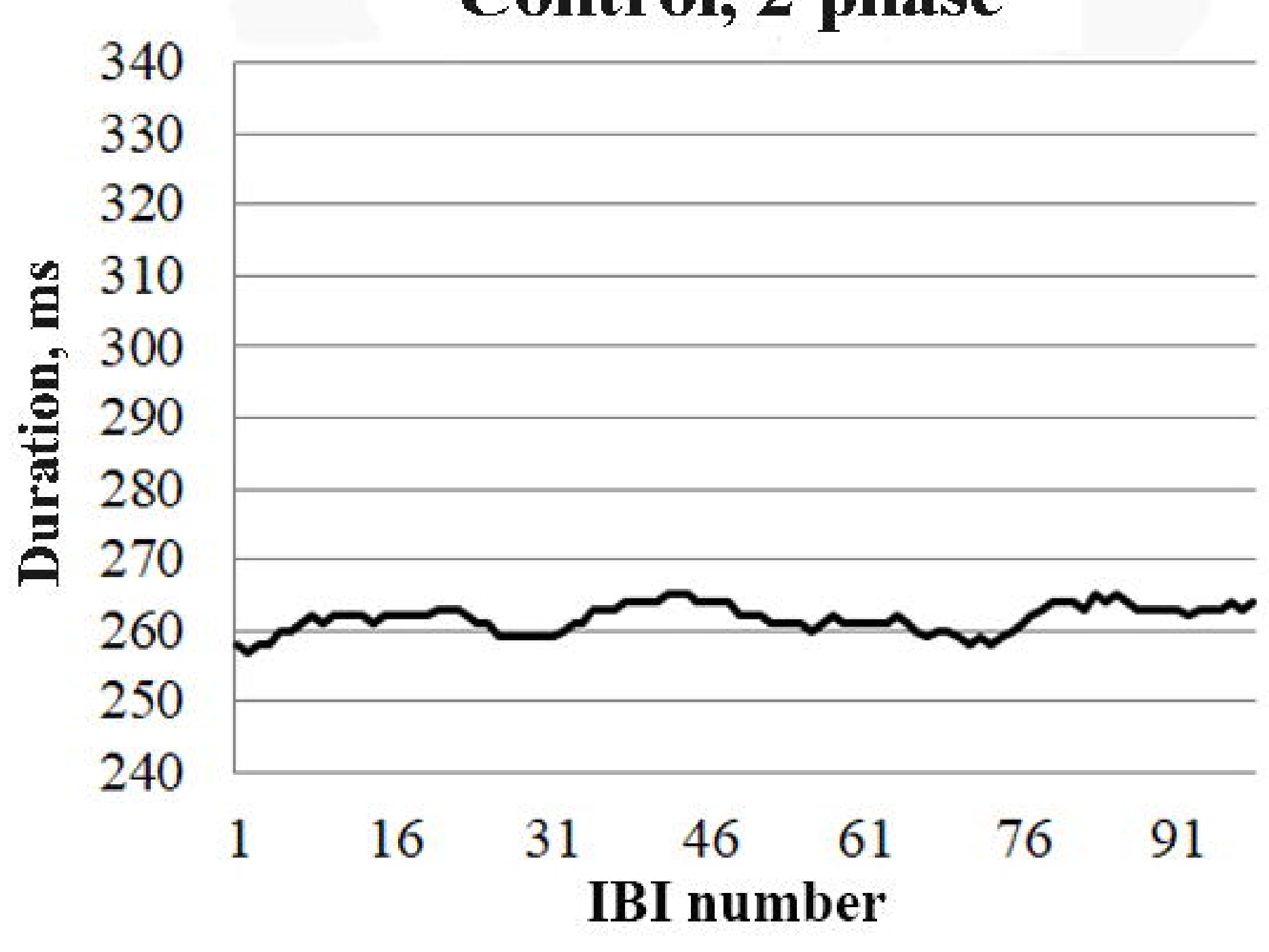

Washout

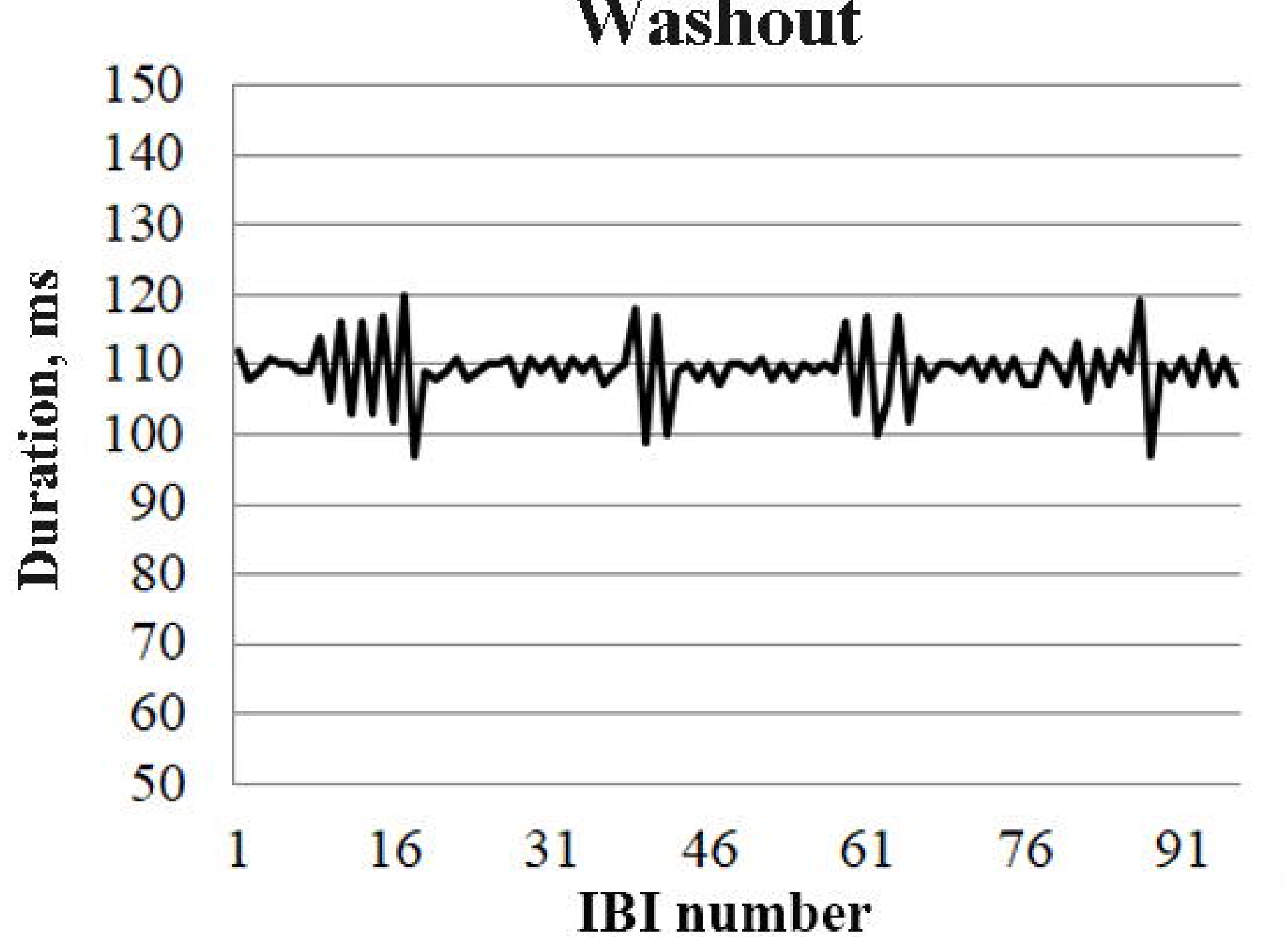

330

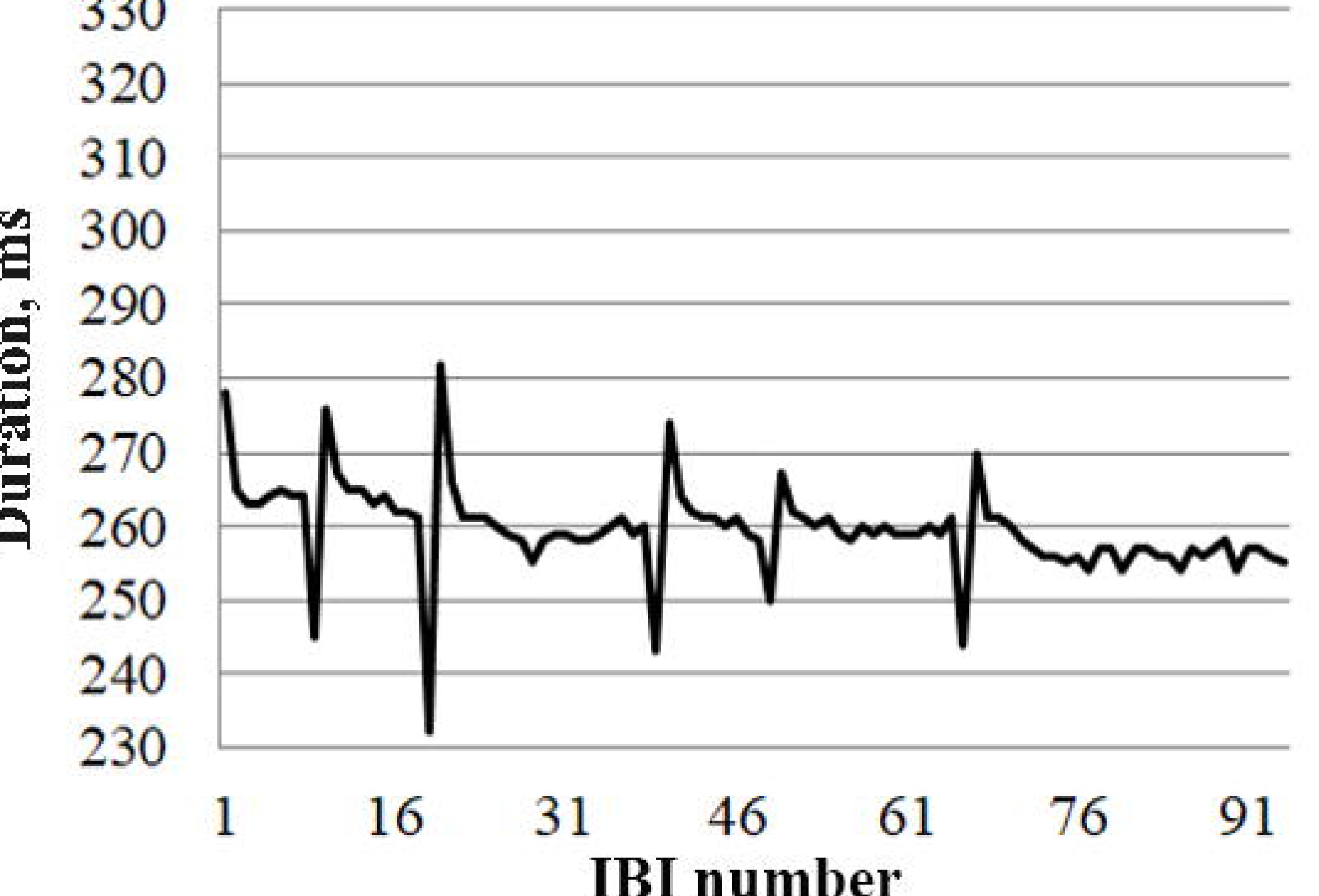
IBI number

D

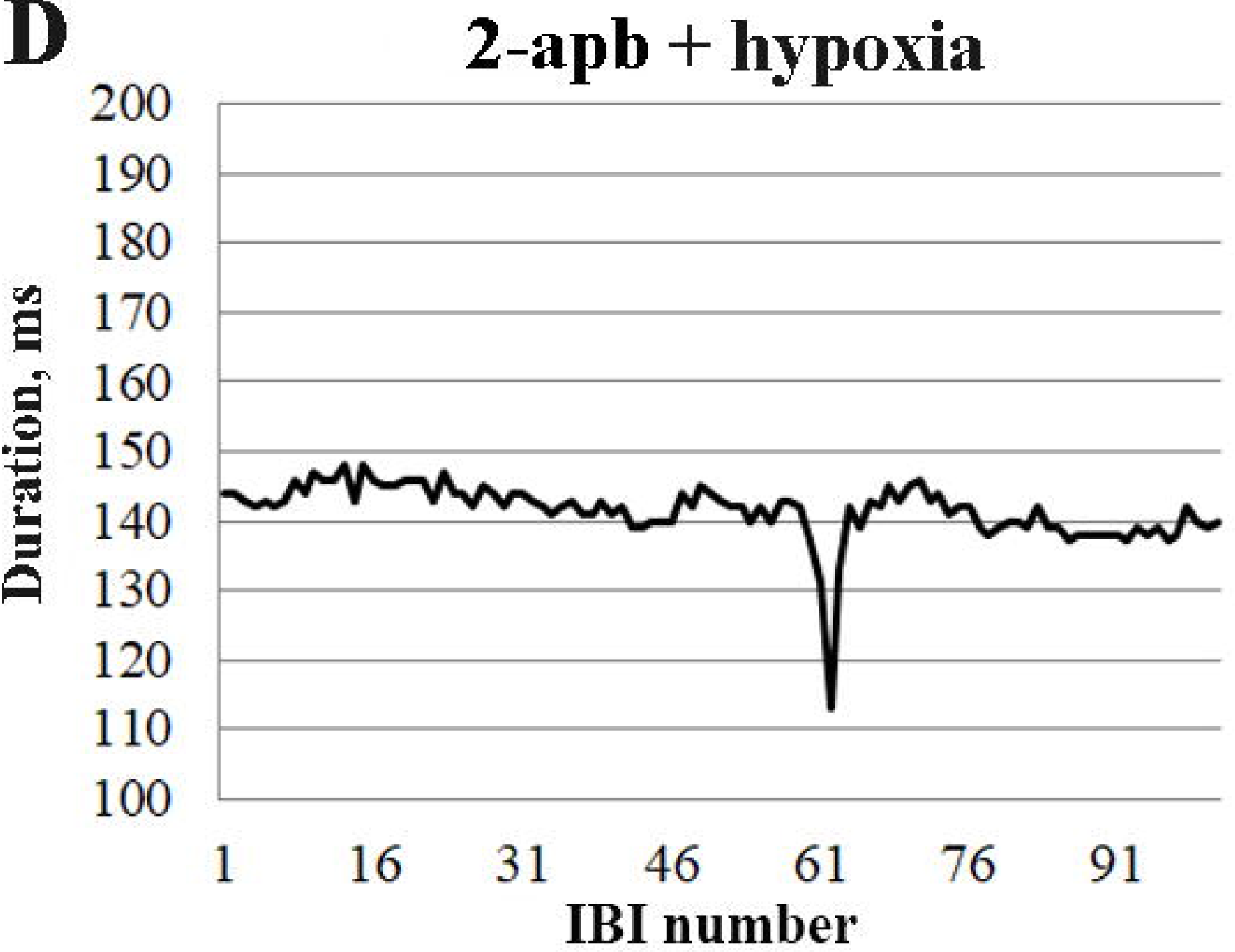

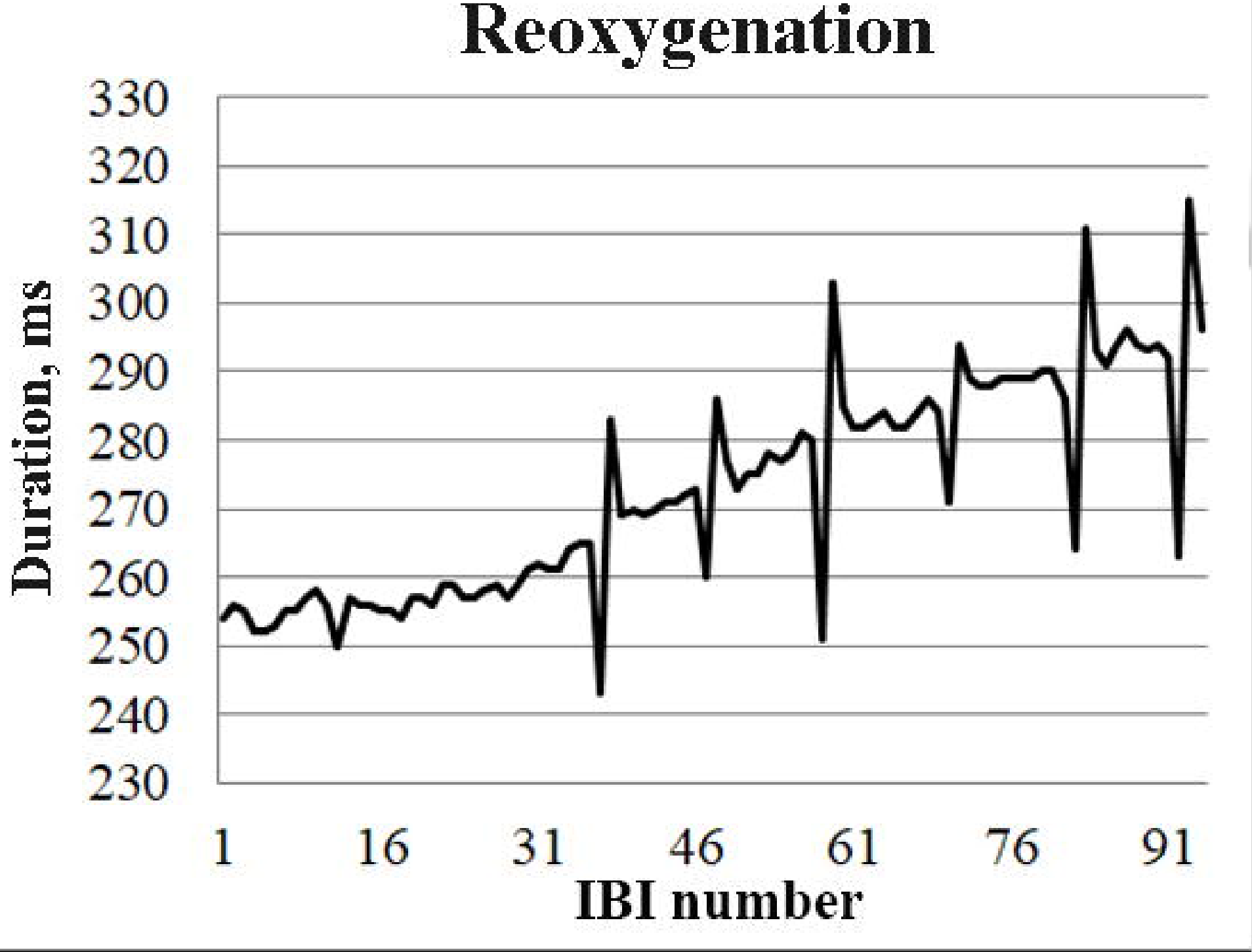

Washout + reoxygenation

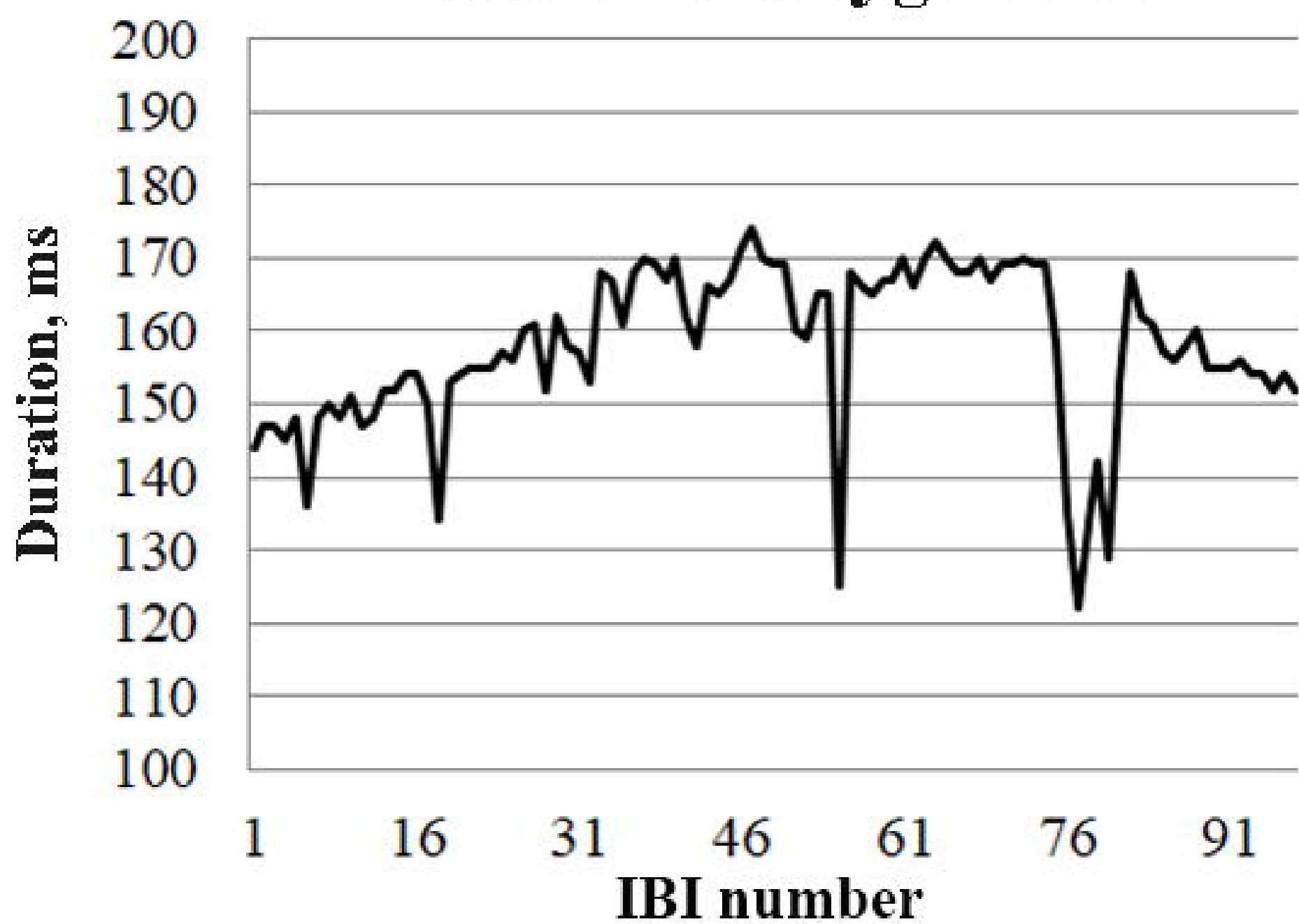


